\title{
Solid Hydrogen Pellet Injection into the ORMAK Tokamak
}
C. A. Foster
R. J. Colchin
S. L. Milora
K. Kim
R. J. Turnbull

\section{OAK RIDGE NATIONAL LABORATORY}




\section{DISCLAIMER}

This report was prepared as an account of work sponsored by an agency of the United States Government. Neither the United States Government nor any agency Thereof, nor any of their employees, makes any warranty, express or implied, or assumes any legal liability or responsibility for the accuracy, completeness, or usefulness of any information, apparatus, product, or process disclosed, or represents that its use would not infringe privately owned rights. Reference herein to any specific commercial product, process, or service by trade name, trademark, manufacturer, or otherwise does not necessarily constitute or imply its endorsement, recommendation, or favoring by the United States Government or any agency thereof. The views and opinions of authors expressed herein do not necessarily state or reflect those of the United States Government or any agency thereof. 


\section{DISCLAIMER}

Portions of this document may be illegible in electronic image products. Images are produced from the best available original document. 


\title{
Printed in the United States of America. Available from National Technical Information Service \\ U.S. Department of Commerce \\ 5285 Port Royal Road, Springfield, Virginia 22161 \\ Price: Printed Copy $\$ 4.00$; Microfiche $\$ 3.00$
}

\begin{abstract}
This report was prepared as an account of work sponsored by the United Slales Government. Neither the United States nor the Energy Research and Development Administration/United States Nuclear Regulatory Commission, nor any of their employees, nor any of their contractors, subcontractors, or their employees, makes any warranty, express or implied, or assumes any legal liability or responsibility for the accuracy, completeness or usefulness of any information, apparatus, product or process disclosed, or represents that its use would not infringe privately owned rights.
\end{abstract}




\author{
Contract No. W-7405-eng-26 \\ Fusion Energy Division
}

\title{
SOLID HYDROGEN PELLET INJECTION INTO THE ORMAK TOKAMAK
}

C. A. Foster, R. J. Colchin, and S. L. Milora

and

K. Kim and R. J. Turnbull

University of Illinois

Urbana, Illinois 61801

Date Published - June 1977

NOTICE This document contains information of a preliminary nature. It is subject to revision or correction and therefore does not represent a final report.

\author{
OAK RIDGE NATIONAL' LABURA'IURY \\ Oak Ridge, Tennessee 37830 \\ operated by \\ UNION CARBIDE CORPORATION \\ for the \\ ENERGY RESEARCH AND DEVELOPMENT ADMINISTRATION
}




\section{THIS PAGE \\ WAS INTENTIONALLY \\ LEFT BLANK}


Abstract ................... . 1

1. Introduction . . . . . . . . . . . . . 1

2. Description of the Experiment . . . . . . . 3

3. Experimental Results . . . . . . . . . . 5

4. Comparison with Theory . . . . . . . . . 14

5. Conclusions . . . . . . . . . . . . . 18

Acknowl edgments . . . . . . . . . . . . 19

References . . . . . . . . . . . . . . 20 


\title{
SOLID HYDROGEN PELLET INJECTION INTO THE ORMAK TOKAMAK ${ }^{*}$
}

\author{
C. A. Foster, R. J. Colchin, and S. L. Milora \\ Oak Ridge National Laboratory \\ Oak. Ridge, Tennessee 37830, USA \\ and
}

K. Kim and R. J. Turnbul1

Department of Electrical Engineering

University of Illinois

Urbana, I1linois 61801, USA

\begin{abstract}
Solid hydrogen spheres were injected into the ORMAK tokamak as a test of pellet refueling for tokamak fusion reactors. Pellets $70 \mu \mathrm{m}$ and $210 \mu \mathrm{m}$ in diameter were injected with speeds of $91 \mathrm{~m} / \mathrm{sec}$ and $100 \mathrm{~m} / \mathrm{sec}$, respectively. Each of the $210-\mu \mathrm{m}$ pellets added about $1 \%$ to the number of particles contained in the plasma. Excited neutrals, ablated from these hydrogen spheres, emitted light which was monitored either by a photomultiplier or by a high speed framing camera. From these light signals it was-possible to measure pellet lifetimes, ablation rates, and the spatial distribution of hydrogen atoms in the ablation clouds. The average measured lifetime of the $70-\mu \mathrm{m}$ pellets was $422 \mu \mathrm{sec}$, and the $210-\mu \mathrm{m}$ spheres lasted $880 \mu \mathrm{sec}$ under bombardment by the plasma. These lifetimes and measured ablation rates are in good agreement with a theoretical model which takes into account shielding of plasma electrons by hydrogen atoms ablated from spherical hydrogen ice.
\end{abstract}

\section{INTRODUCTION}

Tokamak plasmas are initially created by electrical breakdown of a gas prefill. At later times the plasma density typically decays ${ }^{1}$ as particles are.lost to walls and limiters and are not replaced. Several

\footnotetext{
${ }^{*}$ Research sponsored by the Energy Research and Development Administration under contract with the Union Carbide Corporation and the University of Illinois.
} 
mechanisms for refueling tokamaks have been suggested. Currently, tokamaks are otten refueled by puffing gas into the edge of the plasma during the discharge. ${ }^{2-4}$ The problem of maintaining plasma density will become more serious as divertors are introduced, as evidenced by experiments with the DITE ${ }^{5}$ bundle divertor. In fusion reactors, refueling will be necessary to sustain the fusion burn. ${ }^{6-7}$

According to current thinking, gas puffing leads to increases of the density in the center of the plasma by one of two mechanisms, either by transport of energetic charge-exchange neutrals reflested from the vacuum walls 8 or by the inward force of the ware pillch. ${ }^{9-10}$ In future fusion power reactors these mechaniems will likely be inadequatc: energetic neutral particles will be attenuated before they can reach the plasma center, and the Ware pinch will be weaker in larger, hotter plasmàs.

The injection of very high energy neutral particles has also been suggested as a means of refueling tokamak plasmas. ${ }^{11}$ However, only atoms with energies above $100 \mathrm{keV}$ can penetrate into the interior of large plasmas, and particle replacement by high energy neutral particles leads to prohibitively largc densities of stored power.

$\Lambda s$ an alternative to refueling by cold gas (puffing) or by high energy neutral particles, the injection of macroscopic fuel pellets has been suggested. Fuol pellets ablate as they travel through the plasma due to bombardment by energetic electrons and ions. If the pellets are fast enough and large enough, they will reach the center before being completely expended. This method avoids the problems associated with the other refueling schemes, and as a consequence many tokamak reactor. concepts have incorporated this rofueling technique into their designs. 12 The problem of how far a pellel penetratus is a complicated theoretical question which must ultimately be tested by experiment. The work described in this paper is a first attempt to determine experimentally the penetration depth of pelluts into a tokamak-produced plasma.

The theoretical investigation of pellet ablation was initiated by Spitzer et al. in $1954 .^{13}$ Since then, the problem has been attacked 
theoretically by Rose in $1968,{ }^{14}$ Gralnick in $1973,{ }^{15}$ and most recently by Parks et al. ${ }^{16}$ J $\phi$ rgensen et al. ${ }^{17}$ have performed experimental studies of the ablation of hydrogen pellets preinjected into a short-lived (4-5 $\mathrm{\mu sec})$ rotating ion plasma.

This paper describes the results of two experiments, carried out a year apart, in which solid spherical hydrogen pellets were injected into the ORMAK tokamak. ${ }^{2}$ During the first experiments, 70- $\mu \mathrm{m}$ pellets were injected at an average speed of $91 \mathrm{~m} / \mathrm{sec}$; in the second experiments, $210-\mu \mathrm{m}$ pellets were injected with a velocity of $100 \mathrm{~m} / \mathrm{sec}$. Using pellets of differing size has provided a two-point check on theoretical calculations, and on this basis we have made an attempt at extrapolating to larger tokamak plasmas.

Section 2 describes the experimental setup: the pellet injector, plasma conditions, and diagnostics. The results of the experiments are presented in Section 3 and compared with a theoretical model in Section 4. Conclusions including extrapolations to larger tokamaks are given in Section 5 .

\section{DESCRIPTION OF THE EXPERIMENT}

A schematic diagram of the experimental setup is shown in Fig. 1. Spherical pellets of solid hydrogen were created by the breakup and subsequent freezing of a jet of liquid hydrogen flowing from a nozzle. The pellet injector is indicated at the bottom of Fig. 1 and has been described in detail elsewhere. ${ }^{18-19}$ Pellets of $70-\mu \mathrm{m}$ diameter were created at the rate of $1 \times 10^{5} / \mathrm{sec}$, and the $210-\mu \mathrm{m}$ pellets were made at the rate of $2.6 \times 10^{4} / \mathrm{sec}$. For injection into ORMAK two valves were opened, as shown in Fig. 1. Pellets were accelerated by a rapid gas dynamic expansion as they passed along a tube connecting the two valves, and during this acceleration some pellets were fragmented by nonuniform pressure forces. In the following discussion, only full-size pellets will be considered. After passing through both valves, the pellets traversed a $300-\mathrm{cm}$ path before reaching the plasma. 


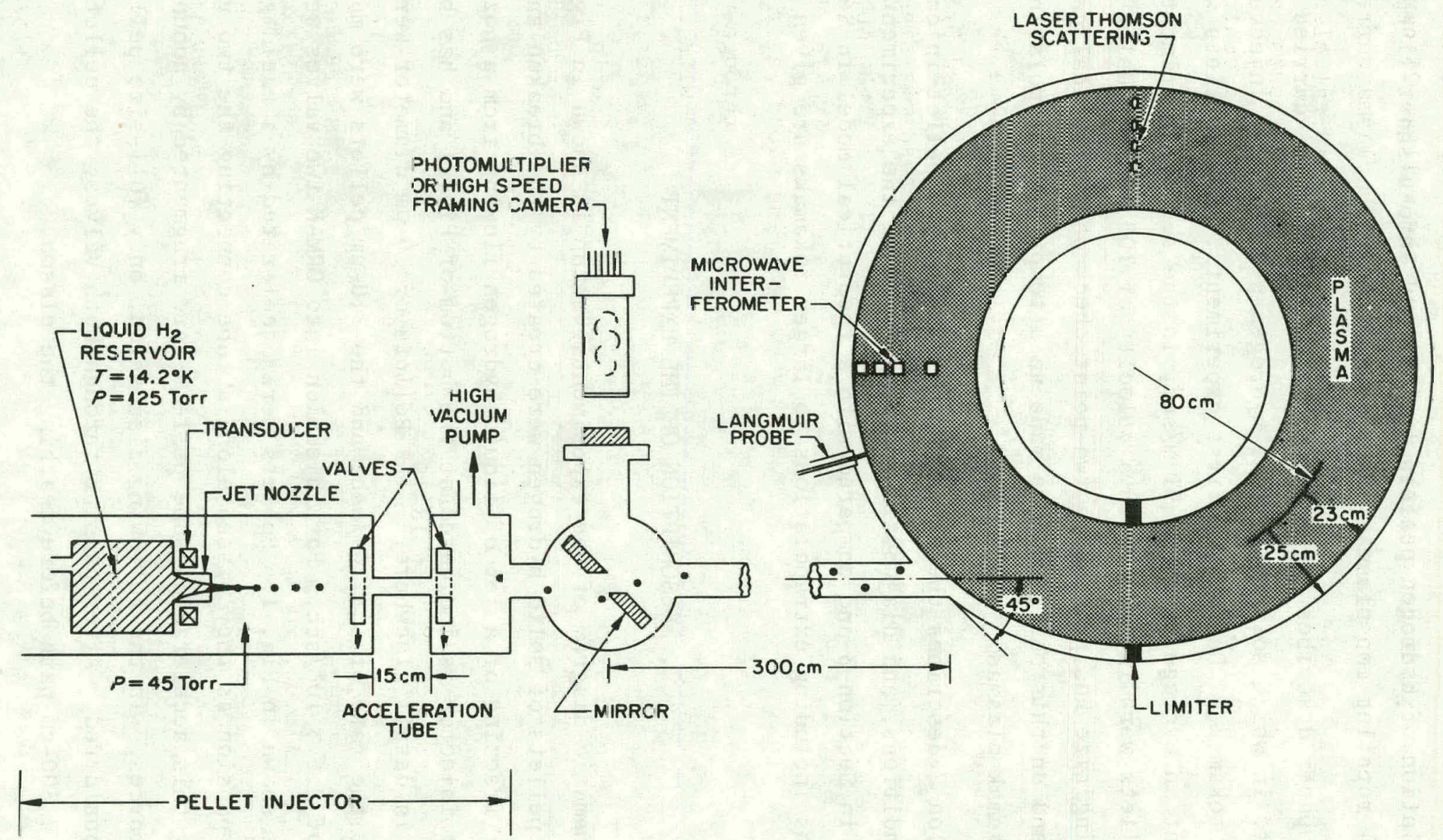

Fig. 1. Schenatic of the pellet injection apparatus and parts of the ORMAK tokamak relevant to pellet injection experiments. The pellet injector and GRMAK cross section are not to scale. The double valve arrangement shown was used in the $210-\mu \mathrm{m}$ pellet experiments. A single valve was used to inject $70-\mu \mathrm{m}$ pellets. 
Pellets were injected at $45^{\circ}$ to the plasma radius of ORMAK, as indicated in Fig. 1. The plasma radius to the 1 imiter is $23 \mathrm{~cm}$, but some cold plasma exists between the limiter and the wall at $25 \mathrm{~cm}$. Most of the $70-\mu \mathrm{m}$ pellet experiments were carried out with plasma currents of $120 \mathrm{kA}, 1$ ine average densities of $2.2 \times 10^{13} \mathrm{~cm}^{-3}$, and central electron temperatures of about $900 \mathrm{eV}$. The $210-\mu \mathrm{m}$ injection experiments had 60-kA plasma current, average densities of about $1 \times 10^{13} \mathrm{~cm}^{-3}$, and central temperatures of $650 \mathrm{eV}$.

Each pellet increased the average plasma density by less than $1 \%$, which was below the sensitivity of the microwave interferometer. Thomson scattering was ineffective in the interaction region near the plasma edge, but electron density and temperature just inside the liner were monitored by a double Langmuir probe. Light from excited hydrogen atoms in the ablation cloud provided the principal diagnostic signal for studying details of the plasma-pellet interaction. This light output was monitored by using either a photomultiplier tube (as in Fig. 1) or a high speed framing camera. Light from the ablating cloud was reflected into these devices by a mirror with a hole in its center through which pellets could pass. The phototube was used in conjunction with an $\mathrm{H}_{\alpha}$ interference filter. The camera (Wollensak ${ }^{\dagger}$ SF2 FASTAX II) was fitted with a $135-\mathrm{mm}$ lens. The camera speed was $7100 \mathrm{frames} / \mathrm{sec}$ during the 210-um pellet experiments and 14,200 frames/sec for the $70-\mu \mathrm{m}$ pellet runs.

\section{EXPERIMENTAL- RESULTS}

Detailed data on pellet lifetimes and ablation rates were derived from the photomultiplier and framing camera data. Most of the examples in this section were taken from the $210-\mu \mathrm{m}$ pellet runs because the larger pellets resulted in better signal-to-noise ratios. Results for the $70-\mu \mathrm{m}$ pellets were qualitatively similar.

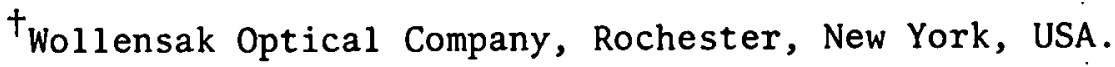


It is possible to infer ablation rates directly from photomultiplier signals because the ablation rate is directly related to rate of production of $H_{a}$ photons. This follows from the fact that plasma electrons ionize hydrogen atoms rather rapidly, so that ablation and loss rates are balanced,

$$
\frac{\mathrm{dN}}{\mathrm{dt}}=\mathrm{N}_{\mathrm{o}} \mathrm{n}_{\mathrm{e}}\left\langle\sigma v_{\mathrm{e}}\right\rangle_{\text {ion }}
$$

where $d N / d t$ is the ablation rate, $N_{0}$ is the number of ablated neutrals in the piasma, $n_{e}$ is the electron plasma density, and $\left\langle u v_{e}\right\rangle_{i o n}$ is the rate coefficient for ionization of neutrals. The number of $\mathrm{H}_{\alpha}$ photons, $N_{\alpha}$, is equal to the neutral excitation rate of hydrogen atoms,

$$
\frac{d N_{\alpha}}{d t} \propto N_{o} n_{e}\left\langle\sigma v_{e}\right\rangle_{\text {exc }}
$$

Combining equations,

$$
\frac{\mathrm{dN}}{\mathrm{dt}} \propto \frac{\mathrm{dN}}{\mathrm{dt}} \frac{\left\langle\sigma v_{\mathrm{e}}\right\rangle_{\text {exc. }}}{\left\langle\sigma v_{\mathrm{e}}\right\rangle_{\text {ion. }}}
$$

i.e., the rate of $\mathrm{H}_{\alpha}$ photon production is directly propnrtional to the ablation rate.

A typical $\mathrm{H}_{\alpha}$ signal arising from excitafton of lleutral atoms in the pellet ablation cloud is shown in fig. 2. The lop erace despiays the $H_{\alpha}$ signal for a full tokamak discharge. In this lrace, the initial light signal peak between 4 and $15 \mathrm{msec}$ was due to $1 \mathrm{jght}$ generated during breakdown of the discharge. The pcllet injection valves (see Fig. 1) were opened at $20 \mathrm{msec}$, and some pellet fragments, which were accelerated ahead of the full-size pellet, caused small light bursts between 33 and $50 \mathrm{msec}$. Light hursts from $210-\mu \mathrm{m}$ pellets the plasma appeared fusl after $50 \mathrm{msec}$. The timing between the opening of the valves and the initial arrival of pellets gives a measure of the pellet velocity. The first two of the full-size pellets are shown on an expanded trace at the bottom of Fig. 2. Fluctuations on the light burst signals are thought to be due to low level MHD instabilities, as similar fluctuations have been observed during gas puffing. The pellet lifetime is determined by measuring the overall duration of a light burst. 


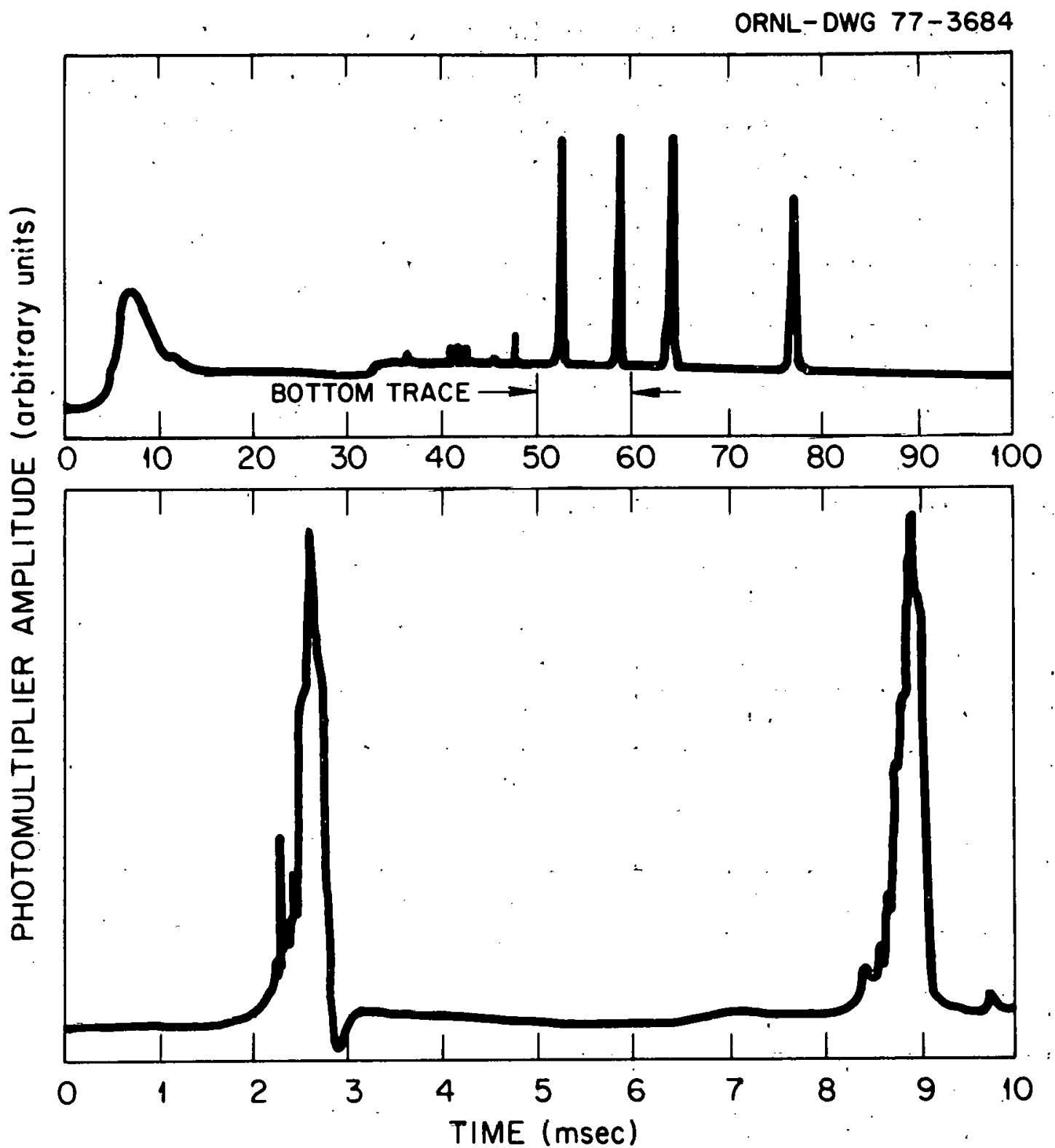

Fig. 2. $\mathrm{H}_{\alpha}$ light signal output from a photomultiplier tube viewing the plasma along the pellet injection path. The top trace records the entire discharge from the time of gas breakdown at $4 \mathrm{msec}$ until the ... plasma current is turned off at $64 \mathrm{msec}$ and subsequently decays. The, bottom trace is a time expansion of a segment of the top trace, as noted.

Table 1 lists data on the lifetimes of $70-\mu \mathrm{m}$ and $210-\mu \mathrm{m}$ diameter pellets for a number of runs. Excluding framing camera data, which contains rather large uncertainties resulting from time between frames, the average lifetime for the $70-\mu \mathrm{m}$ pellets, traveling at a'mean speed of 
Table 1. Pellet data

\begin{tabular}{|c|c|c|c|c|}
\hline $\begin{array}{c}\text { Pellet } \\
\text { Diameter } \\
(\mu \mathrm{m})\end{array}$ & $\begin{array}{l}\text { Peilet } \\
\text { Velocity } \\
\text { (m/sec) }\end{array}$ & $\begin{array}{l}\text { Plàsina } \\
\text { Current } \\
\text { (kA) }\end{array}$ & $\begin{array}{c}\text { Tornidal } \\
\text { Field } \\
\text { (kG) }\end{array}$ & $\begin{array}{l}\text { Pellet } \\
\text { Lifet ime } \\
(\mu s)\end{array}$ \\
\hline 70 & 85 & 120 & 18 & 420 \\
\hline 70 & 90 & 120 & 18 & 400 \\
\hline 70 & 90 & 120 & 18 & 410 \\
\hline 70 & 90 & 103 & 16 & 430 \\
\hline 70 & 90 & 120 & 18 & 450 \\
\hline 70 & 90 & 120 & 18 & 440 \\
\hline 70 & 100 & 120 & 18 & 500 \\
\hline 70 & 90 & 120 & 18 & 490 \\
\hline 70 & 100 & 120 & 18 & 340 \\
\hline 70 & 95 & 120 & 18 & 410 \\
\hline 70 & 85 & 120 & 18 & 360 \\
\hline 70 & 95 & 120 & 18 & $225-375^{a}$ \\
\hline 70 & 85 & 120 & 18 & $200-335^{a}$ \\
\hline 210 & 100 & 60 & 11 & 780 \\
\hline 210 & 100 & 60 & 11 & 890 \\
\hline 210 & 100 & 60 & 11 & 970 \\
\hline 210 & 100 & 60 & 11 & 840 \\
\hline 210 & 100 & $6 n$ & 11 & 900 \\
\hline 210 & 100 & 60 & 11 & 850 \\
\hline 210 & 100 & 60 & 11 & 920 \\
\hline 210 & 100 & 60 & 11 & $840-1120^{a}$ \\
\hline
\end{tabular}

$a_{\text {Data from movie pictures. }}$ 
$91 \mathrm{~m} / \mathrm{sec}$, was $422 \mu \mathrm{sec}$. The average lifetime of the $210-\mu \mathrm{m}$ pellets was $880 \mu \mathrm{sec}$ and their speed was $100 \mathrm{~m} / \mathrm{sec}$. The path lengths of these pellets in the plasma were 3.8 and $8.8 \mathrm{~cm}$; and because they were injected at a $45^{\circ}$ angle, their radial penetration depths were 2.7 and $6.2 \mathrm{~cm}$.

Figure 3 shows data taken from three different 210- $4 \mathrm{~m}$ pellet light bursts. By overlapping data points, it is possible to deduce the general ablation rate characteristics of a pellet.moving through the plasma.

ORNL-DWG 76-19412.

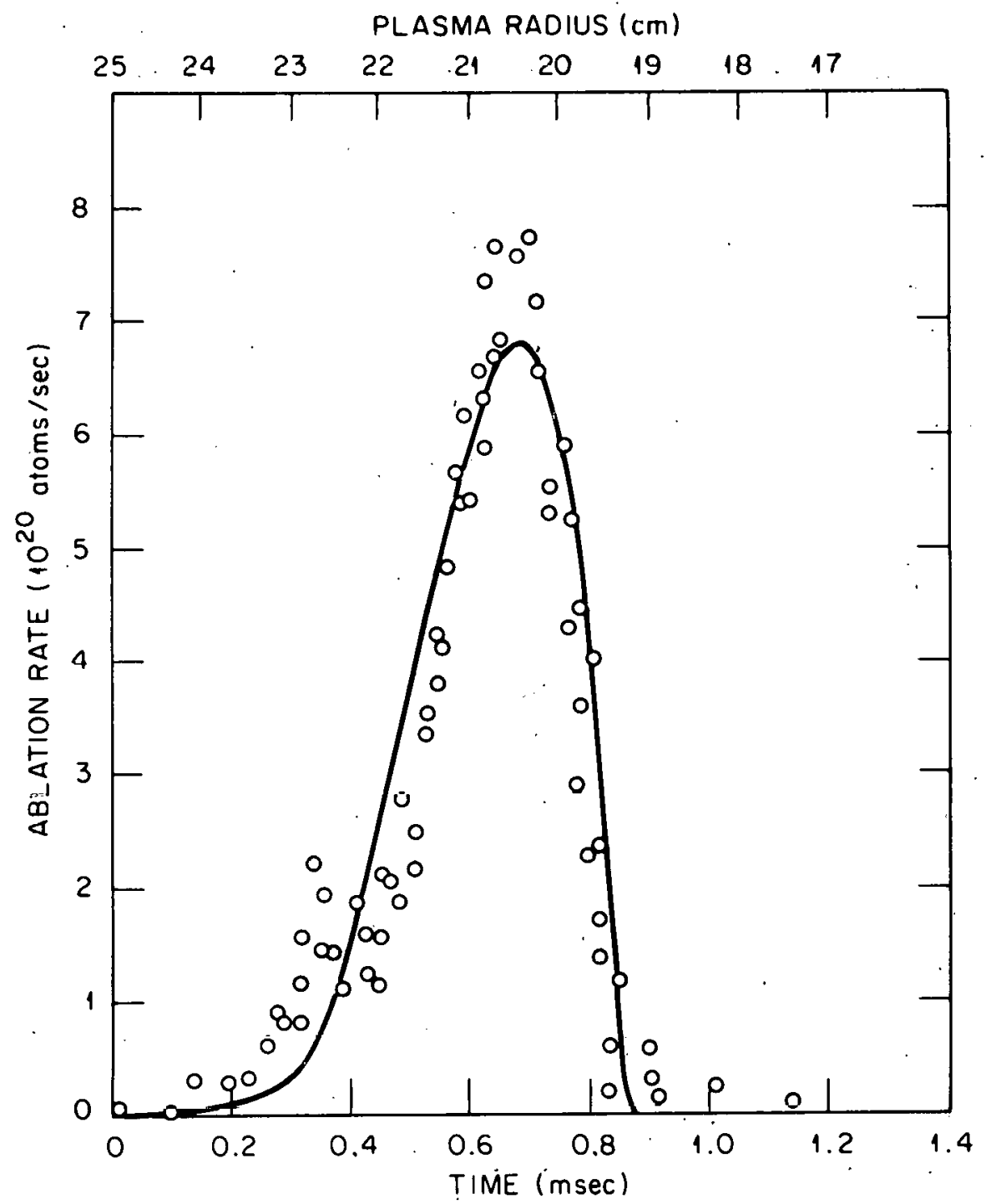

Fig. 3. Superposition of $\mathrm{H}_{\alpha}$ light signals from three 210- $\mu \mathrm{m}$ pellet light bursts, as detected by a photomultiplier. The ablation rate was derived by equating the integrated light signal to the pellet mass. The solid curve is the calculated ablation rate (see Section 4). 
The ablation started off rather slowly in the tenuous plasma outside the limiter, reached a maximum, and dropped quickly to zero as the last of the pellet was vaporized. From the figure the lifetime is seen to be near the 880-usec average obtained from Table 1 .

Data from four 70- $\mu \mathrm{m}$ pellet light bursts are shown in Fig. 4. This data is similar to that of Fig. 3, except that ablation rates are generally much lower and the lifetime is shorter. The lifetime, as measured from the data in Fig. 4, is near to the $422-\mu \mathrm{sec}$ average 1 ifetime obtained from Table 1 .

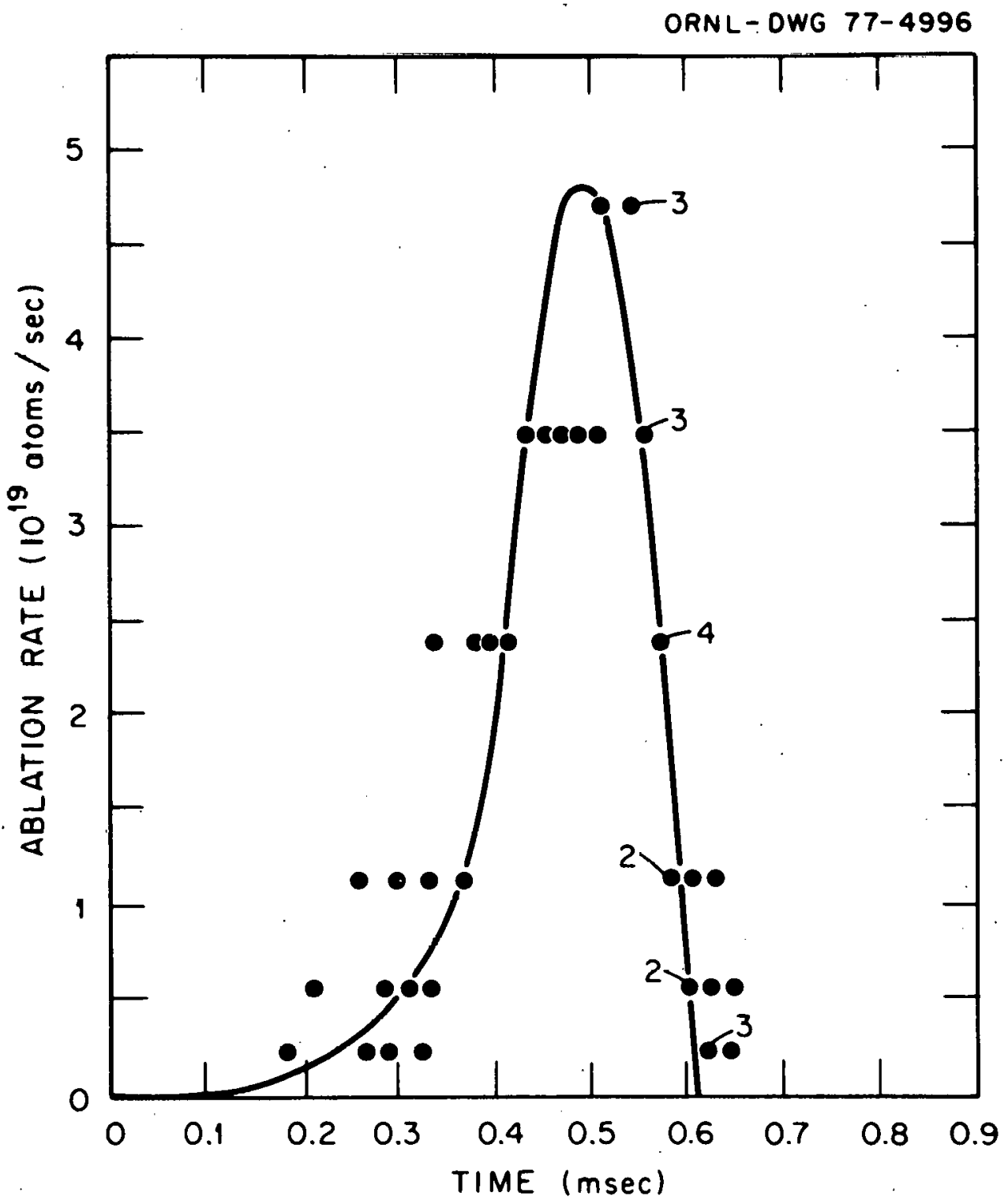

Fig. 4. Superposition of $H_{\alpha}$ light signals from four 70- $\mu$ m pellet light bursts, as detected by a photomultiplier. The ablation rate was measured as in Fig. 3 , and the solid curve was calculated using the theory outlined in Section 4. 
A more graphic illustration of the plasma-pellet ablation was obtained from fast framing camera pictures. The film was sensitive only to visible light, and no filters were used. Figure 5 shows a sequence of six frames encompassing the lifetime of one $210-\mu \mathrm{m}$ pellet. As the pellet entered the plasma, the intensity of the ablation cloud grew. The half width of the largest ablation cloud was 50 times the size of the pellet. In the last frame the pellet was near extinction. As can be seen from a close examination of the last two frames, the pellet path deviated from a straight line near the end of its life. Motion across the plane of the film caused the ablation cloud to have a slightly noncircular appearance in the last frame. Taking into account the optics of the system and a $30^{\circ}$ tilt of the camera, the pellet motion curved in the toroidal direction (i.e., along the toroidal magnetic field in ORMAK).

The pellet speed and lifetime can also be determined from the framing camera data by measuring distances on the film and, by knowing the film speed, converting these distances into time. This information is also given in Table 1 .

Microdensitometer scans of the ablation cloud are shown in Fig. 6. The data for this figure were taken by scanning the film of Fig. 5 with an 8 - $\mu \mathrm{m}$-wide slit and recording transmitted 1ight. In Fig. 6 the first record of the ablation cloud was assumed to occur one frame (140 $\mu \mathrm{sec})$ after the pellet entered the tenuous plasma between the wall and the limiter. With this assumption, the lapsed time is in excellent agreement with the average pellet lifetime.

The curvature of the pellet away from its injection path is also illustrated in Fig. 6. This curvature has not yet been fully explained, but preliminary calculations indicate that it may be due to a net reaction force arising from an imbalance in the ablation rate on opposite sides of the pẹlet. 
ORNL-DWG $77-3683$

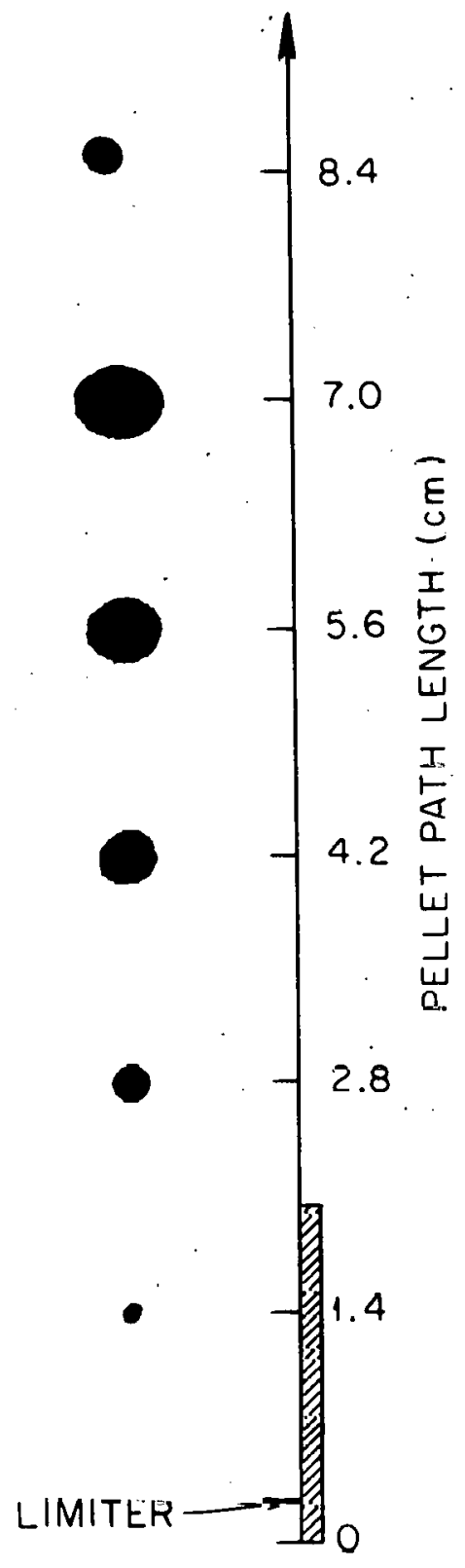

Fig. 5. Enlargement of movie tilm exposed during the lifetime of a 210- $\mu \mathrm{m}$ pellet. A distance scale is shown for reference. On this scale it has been assumed that the first frame was exposed $140 \mathrm{\mu sec}$ after the pellet entered the plasma chamber. A negative of the film is displayed, so that 1 ight from the pellet cloud appears as dark circles. 


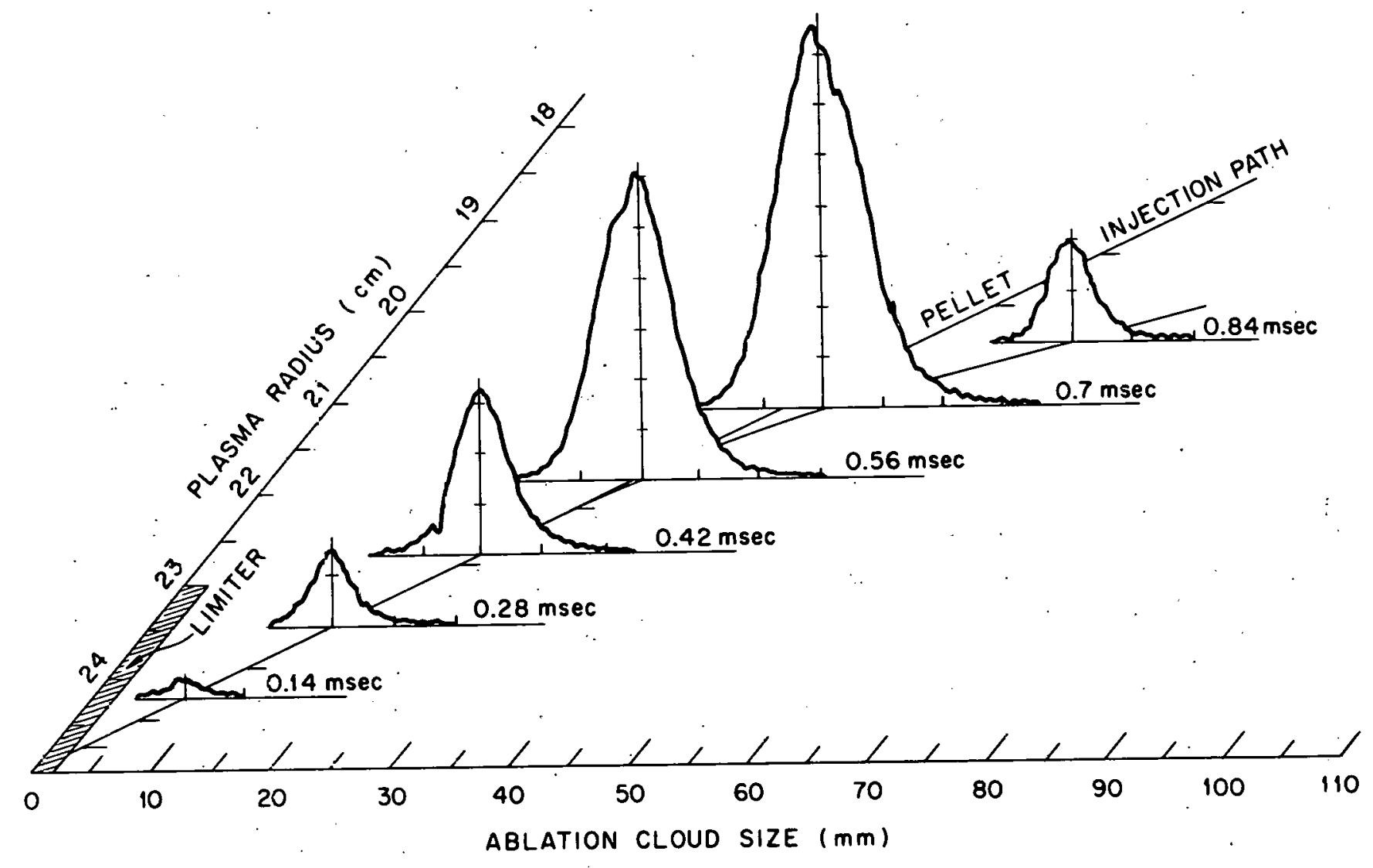

Fig. 6. Microdensitometer scans of the movie film displayed in Fig. 4. The vertical scale gives the ablation cloud brightness, each vertical division representing $4 \%$ light transmission through the movie film. The horizontal axis is a scale of distance along the toroidal field showing the size of the ablation cloud. The third axis shows the radial penetration distance of the pellet into the plasma. 


\section{COMPARISON WITH THEORY}

Among the experimental results which were presented in Section 3, the data on the lifetime and ablation rate are subject to direct comparison with approximate theoretical values. The theory to be employed for this comparison is that of an ablating solid hydrogen pellet in a plasma, as developed recently by Parks et al. ${ }^{16}$ The essential features of the theoretical model are as follows: neutral molecules evaporate from the pellct as a result of its elevated surface temperature and inrtantly form a quasi-steady neutral ablation cloud around the pellet. The inrident electron energy flux is then shielded by this ullation cloud, with musl of tho flux gning into accelerating and lieating the cloud. As a result, only a fraction of the incident electrun encrgy flux reaches the surface of the pellet, raising its surface temperature to a point where the incoming energy is balanced by the energy lost through vaporization. The vaporization rate, in turn, determines the total integrated neutral gas cloud density.

A slightly modified version of the original model is used here. It differs principally in that the hydrodynamic hehavior of the ablation cloud is treated in more detail ${ }^{20}$ and the sonic fluw approximation is discarded in favor of self-consistent transonic solutions. Still, the key elements and overall simplicity of the original model are retalned. In this model the ablation rato is given in terms of the local values of electron energy, $E_{e_{\infty}}(\mathrm{eV})$, and density, $\mathrm{n}_{\mathrm{e}_{\infty}}\left(\mathrm{cm}^{-3}\right)$, by two coupled ordinary differential equations. ${ }^{20}$ The first equation, which incorporates the concept of a shield, expresses the amount of material that the pellet must supply in order to slow electrons down to an arbitrary energy $E_{E_{0}}$ before they strike the pellet surface. In terms of the ablation rate, $\mathrm{dN} / \mathrm{dt}$, this shielding requirement ruduces to

$$
\begin{aligned}
\frac{d N}{d t} & \equiv 4 \pi n_{s} r_{p}^{2} \frac{d p}{d t} \\
& =5.58 \times 10 \frac{{ }^{n} e_{\infty}^{1 / 3}}{M^{1 / 3}} E_{e_{\infty}}^{1 / 6} r_{p}^{4 / 3}\left[L\left(E_{e_{\infty}} / 2\right)\right]^{1 / 3} \int_{E_{e_{0}}}^{E_{e}} \frac{d E_{e}}{L\left(E_{e}\right)}
\end{aligned}
$$


where $L\left(E_{e}\right)$ is a function representing the cumulative loss of energy of electrons in molecular hydrogen by inelastic collisions. ${ }^{21} L\left(E_{e}\right)$ is approximated analytically by the expression

$$
L\left(E_{e}\right)=\left(2.35 \times 10^{14}+4 \times 10^{11} E_{e}+\frac{2 \times 10^{17}}{E_{e}^{2}}\right)^{-1}\left(e V-\mathrm{cm}^{2}\right)
$$

The second equation is an expression of conservation of energy applied at the surface of the receding pellet whereby the incident energy flux is equated to the rate of cooling by evaporation of molecular hydrogen,

$$
\frac{\mathrm{dN}}{\mathrm{dt}}=2.16 \times 10^{10} \mathrm{r}_{\mathrm{p}}^{2} \mathrm{n}_{\mathrm{e}_{\infty}} \mathrm{E}_{\mathrm{e}_{\infty}}^{1 / 2} \mathrm{E}_{\mathrm{e}_{0}}
$$

In the above equations, $\frac{\mathrm{dN}}{\mathrm{dt}}$ is the ablation rate in atoms per second, $\mathrm{n}_{\mathrm{s}}$ is the number density of atoms in the solid, $r_{p}$ is the instantaneous pellet radius in centimeters, $M$ is the molecular weight of the fuel, and $E_{e_{j}}$ is the energy (in $\mathrm{eV}$ ) with which electrons strike the pellet surface. The latter is usually much smaller than the energy of the electrons external to the shielding gas cloud, $E_{e_{\infty}}$. Together, these equations completely determine the temporal behavior of the pellet radius (and therefore the ablation rate) for any prescribed values of electron temperature and density and initial pellet size. In particular, direct comparison with experimental observation follows from knowledge of the pellet speed and trajectory and given tokamak plasma conditions.

Numerical solutions were obtained for the approximate conditions under which the 210-um experiments were performed using the following spatial temperature and density profiles:

$$
\begin{aligned}
& \left.\begin{array}{l}
\mathrm{T}_{\mathrm{e}_{\infty}}(\mathrm{eV})=125[1-(\mathrm{r} / 25)] \\
\mathrm{n}_{\mathrm{e}_{\infty}}=25 \times 10^{11}[1-(\mathrm{r} / 25)]
\end{array}\right\} \begin{array}{l}
23 \mathrm{~cm} \leq \mathrm{r} \leq 25 \mathrm{~cm} \\
\text { (between 1imiter edge and liner) }
\end{array} \\
& \left.\begin{array}{l}
\mathrm{T}_{\theta_{\infty}}(\mathrm{eV})=10+513[1-(\mathrm{r} / 23)] \\
\mathrm{n}_{\mathrm{e}_{\infty}}=2 \times 10^{11}+1.75 \times 10^{13}\left[1-(\mathrm{r} / 23)^{2}\right]^{1.5}
\end{array}\right\} \begin{array}{l}
15.6 \mathrm{~cm} \div \mathrm{r} \leq 23 \mathrm{~cm} \\
(\text { within discharge) }
\end{array}
\end{aligned}
$$

where $\mathrm{r}$ is the plasma radius. 
These profiles were chosen so as to best fit the results of the ORMAK temperature and density measurements relevant to this experiment. The piecewise linear temperature profile is consistent with the Langmuir probe and laser Thomson scattering measurements made at the $23.5-\mathrm{cm}$ and 15.6-cm positions, respectively. The assumed density profiles are in agreement with the Langmuir probe data and satisfy the line average value $\left(\sim 1 \times 10^{13} \mathrm{~cm}^{-3}\right)$ obtained from microwave interferometer measurements. The three halves power law of the radial density dependence is typical of low current ORMAK discharges. ${ }^{1}$ Calculations were also made with differently shaped, but consistent, profiles to test the sensitivity of the model to this parameter.

Finally, these profiles have been used to determine the instantaneous electron density and temperature along the injection path. Pellets were injerted at $100 \mathrm{~m} / \mathrm{sec}$ into the edge plasma along a path that makes an angle of $45^{\circ}$ with respect to the plasma radius.

In Fig. 7 the results of calculations for different density profiles are compared. The plasma density profile between the liner and limiter edge for all these cases $(0-0.3 \mathrm{msec})$ is held constant, but the plasma density within the main discharge varies according to the indicated power laws. The more steeply rising profiles give rise to more rapid evaporation and slightly shorter lifetimes, alchough the deperdence is less than linear as indicated by the form of Eqs (1) and (2). All these profiles could be said to give good agreement with the data, but the preferred profile (three-halves power) best represents lhe uverall observed results.

The comparison with experiment is shown by the solid line in Fig. 3 . As concerns the pellet lifetime and general shape of the ablation curve, the agreement is good. The inilial rapid rise in the ablation rale is a distinct feature of the experimental results which the theory does not reproduce. One possible explanation is that the temperature and/or density at the plasma edge is somewhat higher than the values used in the calculation. A factor of 2 increase in both temperature and density at the limiter edge would be sufficient to raise the initial part of the theoretical curve to the level of the experimental observations, and 


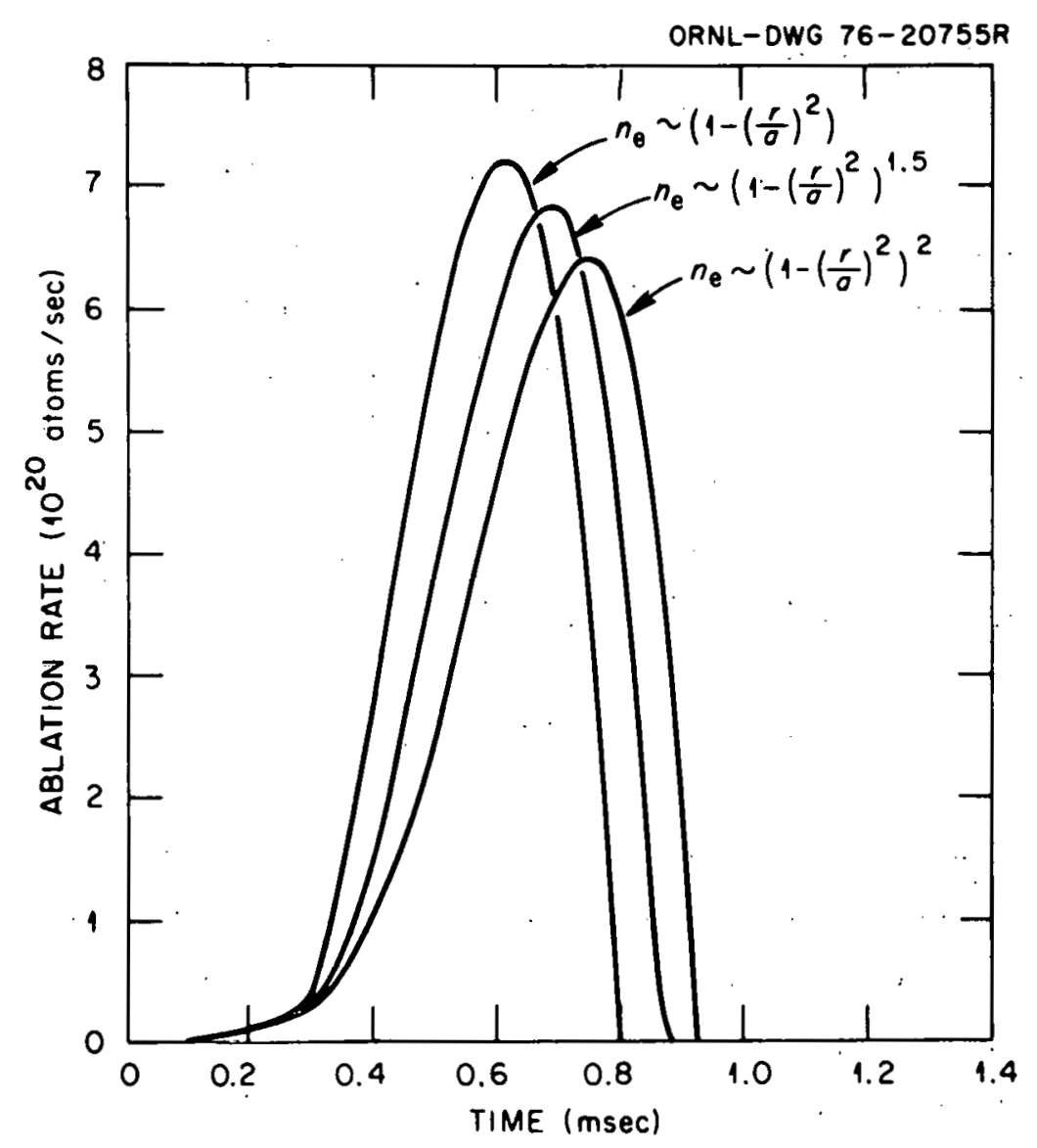

Fig. 7. Ablation rates for 210- $\mu$ m-diameter pellets calculated for three different electron density profiles.

these new plasma conditions would still be within the range indicated by the Langmuir probe measurements. The assumed plasma profiles could also be somewhat erroneous because detailed information at the plasma edge is prcsently not available. A $1-\mathrm{cm}$ uncertainty in plasma position with respect to the liner could also be a contributing factor.

The ablation cloud shields the pellet mainly from plasma electrons, and the amount of shielding depends on the plasma parameters as well as on the resulting density of the cloud. Calculations for the framing camera data of Figs 5 and 6 show that only about $8 \%$ of the incoming electron energy was shielded from reaching the pellet at the time of the first exposure at $140 \mathrm{\mu sec}$. At the time of the largest cloud, $700 \mathrm{\mu sec}$, $75 \%$ of the incoming electron energy was shielded by the ablation cloud. 
The operating conditions under which the 70- $\mu \mathrm{m}$ pellet experiments were performed differed from the $210-\mu \mathrm{m}$ series in that the density was about a factor of 2 larger and the temperature was perhaps $50 \mathrm{eV}$ greater at the outermost laser diagnostic station. The results of the calculation performed with the appropriate plasma parameters are shown in

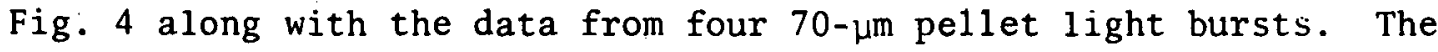
experimental record behaves in a fashion similar to the $210-\mu \mathrm{m}$ series except that the background fluctuation level was larger in comparison to the lower signal level. The signal lcvol was reduced because ablation rates were an order of magnitude smaller, as suggested by Eq. (2).

\section{CONCLUSIONS}

The injection of $70-\mu \mathrm{m}$ and $210-\mu \mathrm{m}$ pellets into tokamak plasmas has produced results which are consistent with a relatively simple theoretical model. This model explains both the lifetime of the pellets and their ablation time history, as observed by light signals emanating from excited hydrogen atoms in the gas cloud surrounding the pellets.

The pellets used in these experiments were only large enough to penetrate into the outer few centimeters of the ORMAK plasma. It is clear that larger pellets with higher velnctites are needed to fuel even today's tokamaks. The theory discussed in section 4 predicts that pellet lifetimes are proportional to the flve-lhirds powor of the pellet radius. However, pellets cannot be made arbitrarily large; their size must be limited so as to contributc only a small fraction to the ions already present in the plasma. This limitation places a burden on increased pellet velocity. Table 2 gives predictions of the velocity to which pellets must he accelerated if they are to reach two thirds of the distance to the center of several tokamaks. Each pellet is assumed to contain $10 \%$ of the ion content of the tokamak, and injection is perpendicular. Central values for $\mathrm{T}_{e}$ and $\mathrm{n}_{\mathrm{e}}$ are 1 isted in Table 2 , and the electron temperature profile is taken as $\left[1-(r / a)^{2}\right]^{2}$ while the electron density radial profile is assumed to vary as $\left[1-(r / a)^{2}\right]$. The extrapolations in Table 2 should be viewed with some caution, because the 
simple physical picture assumed in Section 4 may be inadequate in the hotter, denser plasmas of larger tokamaks.

Table 2. Estimates of experimental pellet fueling requirements

\begin{tabular}{lccccc}
\hline Device & \multicolumn{3}{c}{ Device Characteristics } & $\begin{array}{c}\text { Pellet } \\
\text { Radius } \\
\left(10^{6} \mathrm{~m}\right)\end{array}$ & $\mathrm{n}_{\mathrm{e}^{\left(\mathrm{m}^{-3}\right)}}$ \\
\cline { 2 - 6 } & $\mathrm{a}(\mathrm{m})$ & $\mathrm{T}_{\mathrm{e}}(\mathrm{keV})$ & $\begin{array}{c}\text { Velocity } \\
(\mathrm{m} / \mathrm{sec})\end{array}$ \\
\hline ORMAK & 0.23 & 1.0 & $7 \times 10^{19}$ & 250 & 2500 \\
ISX & 0.25 & 1.0 & $7 \times 10^{19}$ & 285 & 2500 \\
PDX & $0.47 / 0.57$ & 1.0 & $3 \times 10^{19}$ & 400 & 2000 \\
PLT & 0.45 & 1.7 & $5 \times 10^{19}$ & 410 & 4000 \\
\hline
\end{tabular}

ACKNOWLEDGMENTS

We would like to thank the ORMAK operating crew, especially P. H. Edmonds, A. C. England, P. W. King, D. H. McNeil1, M. Murakami, and W. Namkung. C. D. Hendricks was responsible for initiating work on the pellet injector. For their continuing support and encouragement throughout the duration of this project, we would like to thank L. A. Berry, J. F. Clarke, and L. D. Stewart. 


\section{REFERENCES}

1. L. A. Berry et al., in Plasma Physics and Controlled Nuclear Fusion Research (Proc. 5th Int. Conf. Tokyo, 1974) 1, IAEA (1975) 101.

2. L. A. Berry et al., in Plasma Physics and Controlled Nuclear Fusion Research (Proc. 6th Int. Conf. Berchtesgaden, 1976), Paper CN-35/A4-1, to be published by IAEA.

3. E. Apgar et al., in Plasma Physics and Controlled Nuclear Fusion Research (Proc. 6th Int. Conf. Berchtesgaden, 1976) Paper CN-35/A5, to be published by IAEA.

4. D. Meissel et al., in PLasma Physics and Controlled Nuclear Fusiur Research (Proc. 6th Int. Conf. Berchtesgaden, 1976) Paper CN-35/A6, to be published by IAEA.

5. J. W. M. Paul et al., in Plasma Physics and ControlZed Nuclear F'usion Research (Proc. 6th Int. Conf. Berchtesgaden, 1976) Paper CN-35/A17, to be published by IAEA.

6. B. Badger et al., University of Wisconsin Report UWFDM-150 (1975).

7. J. F. Clarke and D. G. McAlees, Oak Ridge National Laboratory, ORNL/TM-5692 (1976).

8. ก. F. Düchs and D. Pfirech, Bu77. Am, Phys. Sne. 21, 1125 (1976).

9. A. A. Ware, Fhys. Rev. Lett. 25, 916 (1970).

10. H. C. Howe, Buil. Am. Hhys. Soc. 21, 1170 (1976).

11. J. R. McNally, Jr., et al., in Plasma Physice and Controlled Nuclear Fusion Research (Proc. 5th Int. Conf. Tokyo, 1974) 3, IAEA (1975) 511.

12. J. W. Davis and G. L. Kulcinski, Nuct. Fusion 16, 355 (19\%6).

13. L. Spitzer et al., NYO-6047, USAEC (1954).

14. D. J. Rose, Culham Laboratory Technology Division Memorandum No. 82 (1968).

15. S. L. Gralnick, Nucl. Fusion 13, 703 (1973). 
16. P. B. Parks, R. J. Turnbu11, and C. A. Foster, "A Model for the Ablation Rate of a Solid Hydrogen Pellet in a Plasma," (to be published in Nucl. Fusion).

17. L. W. Jфrgensen, A. H. Sillesen, and F. Øster, Plasma Phys. 17, 453 (1975).

18. C. A. Foster, Ph. D. thesis, Dept. of Physics, U. of I11., Urbana, Illinois (1977).

19. C. A. Foster et al., "An Apparatus for Producing Uniform Solid Spheres of Hydrogen," (to be published in Rev. Sci. Instrum.).

20. S. L. Milora and C. A. Foster, Oak Ridge National Laboratory, ORNL/TM-5776 (1977).

21. W. T. Miles, R. Thompson, and A. E. S. Green, J. App Z. Phys. 43, 678 (1972). 


\section{THIS PAGE}

\section{WAS INTENTIONALLY LEFT BLANK}




\author{
1. C. F. Barnett \\ 2. J. F. Clarke \\ 3-13. R. J. Colchin \\ 14-24. C. A. Foster \\ 25. S. L. Milora \\ 26. 0. B. Morgan \\ 27. M. W. Rosentha1
}
28-29. Laboratory Records
30. Laboratory Records, ORNL - RC
31. Y-12 Document Reference Section
32-33. Central Research Library
34. Fusion Energy Division Library
35. Fusion Energy Division Reports Office
36. ORNL Patent Office

\section{EXTERNAL DISTRIBUTION}

37. J. W. Beal, Development and Technology, Division of Magnetic Fusion Energy, Mail Code G-234, Energy Research and Development Administration, Washington, DC 20545

38. C. M. Braams, Fom-Instituut voor Plasma-Fysica, Rijnhuizen, Jutphaas, The Netherlands

39. A. M. Budker, Nuclear Physics Institute, Siberian Academy of Sciences, Novosibirsk 90, U.S.S.R.

40. Piero Caldirola, Laboratorio di Fisica del Plasma ed Elettronica Quantistica del C.N.R., Via Celoria, 16, 20133 Milano, Italy

41. C. T. Chang, Physics Department, Research Establishment Ris $\varnothing$ Danish AEC, Raskilide, Denmark, DF

42. Centre de Recherches en Library, Physique des Plasmas, 21 Avenue des Bains, 1007 Lausanne, Switzerland

43. T. Consoli, Centre d'Etudes Nucleaires de Grenoble, Avenue des Martyrs-38-Grenoble, Republic of France

44. H. S. Cullingford, Development and Technology, Division of Magnetic Fusion Energy, Mail Code G-234, Energy Research and Development Administration, Washington, DC 20545

45. N. A. Davies, Office of Confinement Systems, Division of Magnetic Fusion Energy, Mail Code G-234, Energy Research and Development Administration, Washington, DC 20545

46. S. 0. Dean, Assistant Director, Office of Confinement Systems, Division of Magnetic Fusion Energy, Mail Code G-234, Energy Research and Development Administration, Washington, DC 20545

47. Department of Nuclear Engineering Sciences, 202 Nuclear Science Center, University of Florida, Gainesville, FL 32611

48. Director, Technical Library, Defense Atomic Support Agency, Sandia Base, Albuquerque, NM 87115

49. A. M. Dupas, Documentation S.I.G.N., Department de la Physique du Plasma et de la Fusion Controlee, Association Euratom-CEA sur la Fusion, Centre d'Etudes Nucleaires, BP 85 Centre du Tri, 38041 Grenoble CEDEX, Republic of France

50. 0. C. Eldridge, Department of Physics, The University of Tennessee, Knoxville, TN 37916

51. H. P. Eubank, Plasma Physics Laboratory, Princeton University, P. 0. Box 451, Princeton, NJ 08540 
52. H. K. Forsen, Exxon Nuclear Co., Inc., 777 106th Avenue, NE, Bellevue, WA 98004

53. T. K. Fowler, Lawrence Radiation Laboratory, University of California, P. 0. Box 808, Livermore, CA 94551

54. H. P. Furth, Plasma Physics Laboratory, Princeton University, P. O. Box 451, Princeton, NJ 08540

55. R. W. Gould, Electrical Engineering and Physics Department, B1dg. 116-81, California Institute of Technology, Pasadena, CA 91109

56. H. Grad, Courant Institute, New York University, 251 Mercer Street, New York, NY 10012

57. S. Gralnick, Plasma Physics Laboratory, Princeton University, P. 0. Box 451, Princeton, NJ 08540

58. H. R. Griem. Department of Physics, University of Maryland, College Park, MD 20742

59. I. Gverdsiteli, Physico-Technical Institute, Georgian Academy of Sciences, Sukhumi, U.S.S.R.

60. 0. Hagen, Kernforschungszentrum Karlsruhe, Post Fach 3640, 7500 Karlsruhe 1, Federal Repub11c of Germany

61. A. M. Hamende, International Centre for Theoretical Physics, Trieste, Italy

62. Research Laboratory of Electronics, Attention J. Hewitt, Document Room 36-412, Massachusetts Institute of Technology, Cambridge, MA 02139

63. T. Hiraoka, Japan Atomic Energy Research Institute, Tokai, Ibaraki, Japan

64. T. Hsu, Office of Confinement Systems, Division of Magnetic Fusion Energy, Mail Code G-234, Energy Research and Development Administration, Washington, DC 20545

65. P. Hubert. Service de Recherches sur 1a Fusion Controlee, Centre d'Etudes Nucleaires, Fontenay-aux-Roses (Seine), Republic of France

66. K. Husimi, Institute for Plasma Physics, Nagoya University, Nagoya, Japan

67. H. Ikegami, Nagoya University, Nagoya, Japan

68. V. 0. Jensen, Physics Department, Research Establishment Ris $\varnothing$ Danish AEC, Raskilide, Denmark, DF

69. J. Junker, Max-Planck-Insitut fur Plasmaphysik, Abteilung E2, 8046 Garching bei Munchen, Federal Repubilic of Germany

70. G. D. Kerbe1, Lawrence Livermore Laboratory, University of California, P. 0. Box 808, Livermore, CA 94551

71-81. K. K. Kim, Department of Ëlectrical Engineering, University of Illinois, Urbana, IL 61801

82. E.. E. Kintner, Director, Division of Magnetic Fusion Energy, Mail Code G-234, Energy Research and Development. Administration, Washington, DC 20545

83. E. Komar, D. V. Efremov Scientific Research Institute for Electrophysical Equipment, Leningrad, U.S.S.R.

84. H. E. Knoepfel, Laboratori Gas Ionizzati, Associazione Euratom-CNEN, Casella Postale N. 65, Frascati (Roma), Italy

85. L. L. Lengye1, Max-Planck-Institut fur Plasmaphysik, Abteilung E2, 8046 Garching bei Munchen, Federal Republic of Germany 
86. Librarian, Controlled Thermonuclear Research Library, Lawrence

87. Livermore Laboratory, University of California, P. 0. Box 808, Livermore, CA 94550

88. Librarian, Culham Laboratory, United Kingdom Atomic Energy Authority, Abingdon, Berkshire, England

89. Librarian, Department of Physics and Astronomy, University of Iowa, Iowa City, IA 52240

90. Librarian, Max-Planck-Institut fur Plasmaphysik, 8046 Garching bei Munchen, Federal Republic of Germany

91. Librarian, Physical Sciences Laboratory, P. 0. Box 6, Stoughton, WI 53589

92. Librarian, Plasma Physics Laboratory, Princeton University, P. 0. Box 451, Princeton, NJ 08540

93. Librarian, Q Division Library, Los Alamos Scientific Laboratory, P. 0. Box 1663, Ios Alamos, NM 87544

94. C. E. Max, Lawrence Livermore Laboratory, University of California, P. 0. Box 808, Livermore, CA 94551

95. D. G. McAlees, Research and Technology Center, Exxon Nuclear Co., Inc., 2955 George Washington Way, Richland, WA 99352

96. D. M. Meade, Plasma Physics Laboratory, Princeton University, P. O. Box 451, Princeton, NJ 08540

97. M. R. Murphy, Development and Technology, Division of Magnetic Fusion Energy, Mail Code G-234, Energy Research and Development Administration, Washington, DC 20545

98. T. Ohkawa, General Atomic Company, P. O. Box 81608, San Diego, CA 92138

99. D. Palumbo, Directorate General for Research and Training, Euratom, 51 Rue Belliard, Brussels 5, Belgium

100. P. B. Parks, General Atomic Company, P. 0. Box 81608, San Diego, CA 92138

101. Plasma Laboratory Reading Room, Massachusetts Institute of Technology, Room 20A-222, Cambridge, MA 02139

102. P. A. Politzer, Department of Nuclear Engineering, Massachusetts Institute of Technology, Cambridge, MA 02139

103. F. Prevot, Chef du Service du Confinement des Plasmas, CEA, B. P. No. 6, 92260 Fontenay-aux-Roses, France

104. M. S. Rabinovich, P. N. Lebedev Institute of Physics of the U.S.S.R. Academy of Sciences, Moscow, U.S.S.R.

105. W. Riedmuller, Max-Planck-Institut fur Piasmaphysik, Abteilung E2, 8046 Garching bei Munchen, Federal Republic of Germany

106. Research Information Center, Institute of Plasma Physics, Nagoya University, Nagoya, Japan

107. D. J. Rose, Massachusetts Institute of Technology, Room 24-207, Cambridge, MA 02139

108. M. Salvat, Max-Planck-Institut fur Plasmaphysik, Abteilung E2, 8046 Garching bei Munchen, Federal Republic of Germany

109. G. Schmidt, Plasma Physics Laboratory, Princeton University, P. 0. Box 451, Princeton, NJ 08540

110. J. Schmidt, Plasma Physics Laboratory, Princeton University, P. 0. Box 451, Princeton, NJ 08540

111. F. R. Scott, Electric Power Research Institute, 3412 Hillview Avenue, P. O. Box 10412, Palo $\wedge 1$ to, $C \wedge 94303$ 
112. T. Sekiguchi, University of Tokyo and IPP Nagoya, Tokyo, Japan

113. L. D. Smullin, Massachusetts Institute of Technology, Cambridge, MA 02139

114. J. C. Sprott, Physics Department, University of Wisconsin, Madison, WI 53706

115. L. D. Stewart, Plasma Physics Laboratory, Princeton University, P. O. Box 451, Princeton, NJ 08540

116. C. E. Thomas, Department of Nuclear Engineering, Massachusetts Institute of Technology, Cambridge, MA 02139

117-126. R. J. Turnbul1, 5621 Charlotte Way, Apartment 14, Livermore, CA 94550

127. J. M. Williams, Assistant Director, Development and Technology, Division of Magnetic Fusion Energy, Mail Code G-234, Energy Research and Development Administration, Washington, DC 20545

128. J. T. Woo, Massachusetts Institute of Technology, Room 38-176, Cambridge, MA 02139

129. H. H. Woodson, Chairman, Department of Electrical Englneering, The University of Texas at Austin, Atstin, TX 78712

130. Center for Plasma Physics and Thermonuclear Research, The University of Texas, Physics Building 330, Austin, TX 78712

131. Research and Technical Support Division, ERDA-ORO, P. O. Box E, Oak Ridge, TN 37830

132-158. Technical Information Center, P. O. Box E, Oak Ridge, TN 37830 